\title{
Bone Window Computed Tomography for Detection of Dural Defect Associated with Cervical Ossified Posterior Longitudinal Ligament
}

\author{
Kazutoshi HidA, Yoshinobu IWASAKI, Izumi KOYANAGI, and Hiroshi ABE \\ Department of Neurosurgery, University of Hokkaido School of Medicine, Sapporo
}

\begin{abstract}
Anterior decompression of a cervical ossified posterior longitudinal ligament (OPLL) which involves the dura mater occasionally results in a postoperative cerebrospinal fluid fistula. Bone window computed tomography (CT) was carried out to detect dural defects in 21 patients with cervical OPLL. Twelve of 21 patients had double-layer OPLL, and nine had single-layer OPLL. Dural defects were present in 10 of the 12 patients with double-layer OPLL compared with only one of the nine patients with single-layer OPLL. In addition, greater stenosis of the spinal canal by the OPLL was also associated with dural defect. Preoperative bone window CT can indicate likely locations of dural defect in patients with OPLL.
\end{abstract}

Key words: ossification of posterior longitudinal ligament, myelopathy, cervical stenosis, computed tomography

\section{Introduction}

Anterior decompression of a cervical ossified posterior longitudinal ligament (OPLL) ${ }^{1,2,4,5,10)}$ generally achieves more satisfactory results than posterior decompression. ${ }^{7-9,12,13,15)}$ However, extirpation of the OPLL may result in a dural defect because the ossified ligament is tightly adherent to the dura, or has extended through the dura. ${ }^{2,3]}$ Such a dural defect sometimes causes a cerebrospinal fluid (CSF) fistula when the adjacent arachnoid membrane is injured.

This study investigated whether bone window preoperative computed tomography (CT) can identify the dural defects which often cause postoperative CSF fistulas retrospectively.

\section{Materials and Methods}

Twenty-one patients with cervical OPLL, aged from 32 to 66 years (mean 54 years), underwent preoperative CT using a bone window (window width 15002000 Hounsfield unit [HU], window level 350-450 HU) (Fig. 1). The width and thickness of the OPLL were then estimated and expressed as a percentage of the transverse diameter of the spinal canal

Received May 17, 1996; Accepted September 14, 1996 (\%width) and a percentage of the anteroposterior diameter of the spinal canal (\%thickness) at each level (Fig. 2). The level of maximum compromise was then recorded.

The operating microscope was routinely employed to identify the location and character of dural defects associated with OPLL.

\section{Results}

Tomography and CT of the 21 patients showed that ossified ligaments involved one to six levels (mean 3.1 levels). Thirteen patients had segmental, six had mixed, one had continuous, and one had another type of OPLL. ${ }^{\text {6) }}$ Corpectomies were performed over one to four vertebral levels (mean 1.6).

Bone window CT revealed double layers at the thickest level of the OPLL in 12 patients and a single layer in nine patients. Ten of the 12 patients with a double layer also had dural defects. The other two patients had partial ossification of the dura mater. In contrast, eight of the nine patients with a single layer had intact dura mater.

The patients with dural defect had a \%width of $54.3 \pm 12.3$ (mean \pm SD), and a \%thickness of 57.4 \pm 11.3 (Fig. 3). The patients with intact dura mater had a \%width of $32.6 \pm 7.4$, and a \%thickness of $34.0 \pm 5.4$. These indices significantly differed be- 

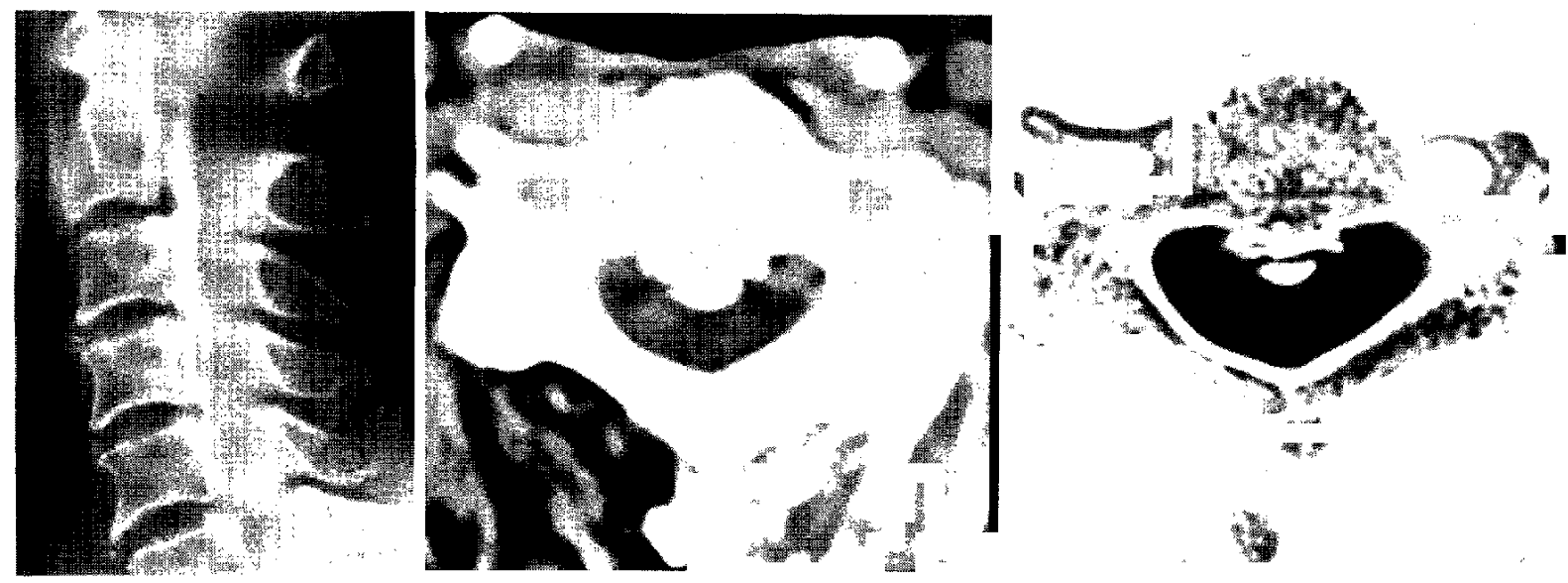

Fig. 1 Representative case of cervical ossified posterior longitudinal ligament (OPLL). left: Tomogram. center: Conventional axial computed tomography (CT) scan at C-4 level (window width 300 Hounsfield unit [HU], window level $56 \mathrm{HU}$ ). right: Bone window CT at C-4 level (window width $1650 \mathrm{HU}$, window level $450 \mathrm{HU}$ ) showing the double-layer OPLL.
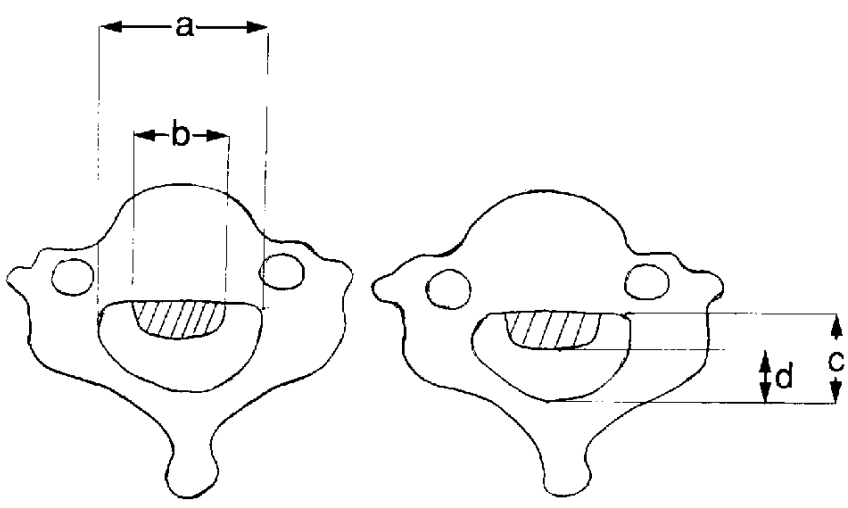

Fig. 2 Measurement of \%width, the relative transverse diameter of the ossified posterior Iongitudinal ligament (OPLL) in the spinal canal (left: b/a); and \%thickness, the relative anteroposterior diameter of the OPLL in the spinal canal [right: $(\mathrm{c}-\mathrm{d}) / \mathrm{c}]$.

tween the two groups (unpaired t-test, $\mathrm{p}<0.001$ ).

\section{Discussion}

The present study showed that bone window CT is useful to evaluate the size of the OPLL and to visualize the configuration.

The relative size of the OPLL to the spinal canal has been used to measure stenosis of the spinal canal due to OPLL. ${ }^{1,3,14,17]}$ The stenosis ratio or percentage narrowing has been measured by tomography ${ }^{1,3]}$ and conventional CT. ${ }^{17\}}$ However, conventional CT using a narrow window width tends to overestimate size.

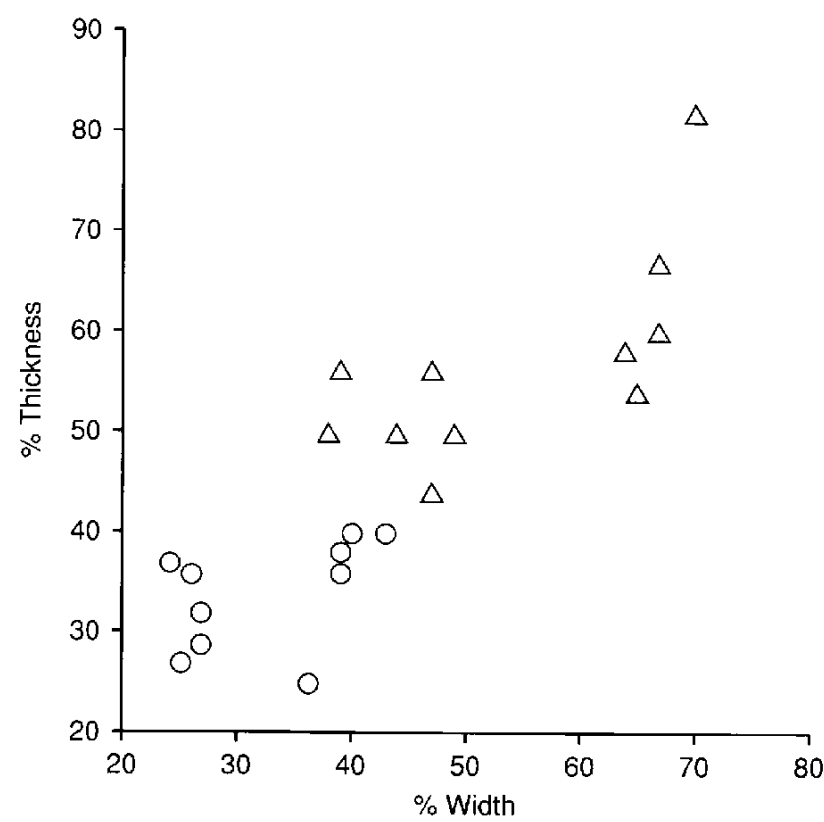

Fig. 3 Relationship between \%width, \%thickness, and dural defect. $\triangle$ : dural defect $(+), \bigcirc$ : dural defect $(-)$.

Patients with the double-layer OPLL were more likely to have a dural defect than patients with single-layer OPLL. Greater stenosis of the spinal canal, indicated by a \%width of over $40 \%$ or \%thickness of over $50 \%$, also indicates a higher possibility of a dural defect.

The posterior longitudinal ligament consists of two layers: the superficial layer located just on the dura mater which bridges three or four vertebrae, 
and the deep layer underlying the vertebra and connecting the adjacent two vertebrae. ${ }^{11,16 l}$ We speculate that the ventral part of the double-layer OPLL indicates ossification of the deep layer, and the dorsal part shows ossification of superficial layer with or without ossification of the dura mater.

We recommend that preoperative bone window CT should be performed for patients with cervical OPLL to identify sites with a double layer and/or $\%$ width $>40$ or \%thickness $>50$ which are likely to be associated with a dural defect and will require extra care during operation.

\section{Acknowledgment}

This study was supported by Grant $2 \mathrm{~A}-9$ from the National Center of Neurology and Psychiatry of the Ministry of Health and Welfare, Japan.

\section{References}

1) Abe $H$, Tsuru $M$, Ito $T$, Iwasaki $Y$, Koiwa $M$ : Anterior decompression for ossification of the posterior longitudinal ligament of the cervical spine. J Neurosurg 55: 108-116, 1981

2) Epstein NE: Ossification of the posterior longitudinal ligament: Diagnosis and surgical management. Neurosurgery Quarterly 2: 223-241, 1992

3) Hanai $\mathrm{K}$, Adachi $\mathrm{H}$, Ogasawara $\mathrm{H}$ : Axial transverse tomography of the cervical spine narrowed by ossification of the posterior longitudinal ligament. J Bone Joint Surg Br 57: 481-484, 1977

4) Hanai K, Fujiyoshi F, Kamei K: Subtotal vertebrectomy and spinal fusion for cervical spondylotic myelopathy. Spine 11: 310-315, 1986

5) Harsh GR, Sypert GW, Weinstein PR, Ross DA, Wilson CB: Cervical spine stenosis secondary to ossification of the posterior longitudinal ligament. $J$ Neurosurg 67: 349-357, 1987

6) Hayashi K, Yabuki T, Kurokawa T, Seki H, Hogaki M, Minoura S: The anterior and the posterior longitudinal ligaments of the lower cervical spine. I Anat 124: 633-636, 1985

7) Hirabayashi K, Watanabe K, Wakano K, Suzuki N, Satomi K, Ishii Y: Expansive open door laminoplasty for cervical spinal stenotic myelopathy. Spine 8: 693699,1983

8) Kamioka $\mathrm{Y}$, Yamamoto $\mathrm{H}$, Tani $\mathrm{T}$, Ishida $\mathrm{K}$, Sawamoto $\mathrm{T}$ : Postoperative instability of cervical OPLL and cervical radiculomyelopathy. Spine 14: 1177-1183, 1989

9) Kirita Y: Posterior decompression for ossification of the posterior longitudinal ligament of the cervical spine. The method of the wide and instantly expansive laminectomy. Orthop Surg 30: 45-49, 1979

10) Kojima T, Waga S, Kubo $Y$, Kanamaru K, Shimosaka $S$, Shimizu T: Anterior cervical vertebrectomy and interbody fusion for multi-level spondylosis and ossifi- cation of the posterior longitudinal ligament. Neurosurgery 24: 864-872, 1989

11) Kubo Y, Waga S, Kojima T, Matsubara T, Kuga Y, Nakagawa Y: Microsurgical anatomy of the lower cervical spine and cord. Neurosurgery 34: 895-902, 1994

12) Nagashima C: Cervical myelopathy due to ossification of the posterior longitudinal ligament. I Neurosurg 37: 653-660, 1972

13) Nakano N, Nakano $T$, Nakano K: Comparison of the results of laminectomy and open-door laminoplasty for cervical spondylotic myelo-radiculopathy and ossification of the posterior longitudinal ligament. Spine 13: 792-794, 1988

14) Nose T, Egashira T, Enomoto T, Maki Y: Ossification of the posterior longitudinal ligament: A clinicoradiological study of 74 cases. J Neurol Neurosurg Psychiatry 50: 321-326, 1987

15) Tomita K, Nomura $S$, Umeda S, Baba H: Cervical laminoplasty to enlarge the spinal canal in multilevel ossification of the posterior longitudinal ligament with myelopathy. Arch Orthop Trauma Surg 107: 148-153, 1988

16) Warwick R, Williams P: Gray's Anatomy, ed 35. London, Longman Group Ltd., 1973, pp 411-412

17) Yamamoto I, Kageyama N, Nakamura K: Computed tomography in ossification of the posterior longitudinal ligament in the cervical spine. Surg Neurol 12: 414-418, 1979

Address reprint requests to: K. Hida, M.D., Department of Neurosurgery, University of Hokkaido School of Medicine, North-15, West-7, Kita-ku, Sapporo 060, Japan.

\section{Commentary}

The authors describe a very important technique to help the surgeon identify which patients are at risk of a dural tear and a CSF leak when operating on patients with OPLL. Their observation of the double shadow is very important as well as the relationship of the percentage thickness against the percentage width in predicting those with dural defect.

Having established these important guidelines, would the authors consider posterior surgery such as an open door laminoplasty if there was a suspicion that the dural involvement extended over several segments.

Alan Crockaro, M.D. Department of Surgical Neurology The National Hospital for Neurology and Neurosurgery London, U.K.

The article by Hida et al. is interesting and helpful. The simple technique of being able to calculate the 
percentage of the canal occupied by the ossified ligament helps the surgeon know whether a CSF leak is likely. The authors analyzed this problem in $21 \mathrm{pa-}$ tients and found that approximately a $50 \%$ compromise in either direction leads to the likelihood of a CSF leak forming. Moreover, the identification of the double layer is extremely helpful.

Because we have been unable to predict those patients who would develop a leak, I have made the practice of performing a lumbar puncture with a lumbar drain preoperatively. The CSF is not drawn out. However, if a dural leak does occur during the surgery, having the drain in place will facilitate the treatment. Certainly it is easier to place a drain in the lum. bar subarachnoid space while the normal CSF pressure is present than after the dura is violated.

I appreciate the contribution made by these authors and will use their technique in the future.

Stewart B. DUNSKER, M.D.

Division of Spinal Surgery

Department of Neurosurgery

University of Cincinnati
Ohio, U.S.A.

This is a very interesting and useful paper for neurosurgeons who perform cervical OPLL surgery. If there is a definite pathological difference between OPLL with and without dural defect, this paper will be more interesting and important.

Unfortunately, the precautions to prevent CSF leak and preserve the arachnoid membrane intact during operation are not described in the manuscript for surgeons who want to treat double-layered OPLL patients.

The authors also do not discuss the difference in morbidity between patients with double-layered OPLL and those with single-layered OPLL.

Tomokatsu HorI, M.D. Division of Neurosurgery Research Institute of Neurological Sciences Faculty of Medicine Tottori University Tottori, Japan 